\title{
A surveillance summary of smoking and review of tobacco control in Jordan

\author{
Adel Belbeisi ${ }^{1}$, Mohannad Al Nsour ${ }^{2}$, Anwar Batieha ${ }^{3}$, David W Brown ${ }^{* 4}$ and \\ Henry T Walke
}

\author{
Address: ${ }^{1}$ Ministry of Health, Amman, Jordan, ${ }^{2}$ Consultant to Centers for Disease Control and Prevention, Atlanta, Georgia, USA, ${ }^{3}$ Jordan \\ University of Science and Technology, Irbid, Jordan and ${ }^{4}$ Centers for Disease Control and Prevention, Atlanta, Georgia, USA \\ Email: Adel Belbeisi - epijor@wanadoo.jo; Mohannad Al Nsour - mohannadnsour973@yahoo.com; Anwar Batieha - batieha@just.edu.jo; \\ David W Brown* - dbrown6@cdc.gov; Henry TWalke - hwalke@cdc.gov \\ * Corresponding author
}

Published: I December 2009

Globalization and Health 2009, 5:18 doi:10.1 186/1744-8603-5-18
Received: I October 2009

Accepted: I December 2009

This article is available from: http://www.globalizationandhealth.com/content/5/I//8

(C) 2009 Belbeisi et al; licensee BioMed Central Ltd.

This is an Open Access article distributed under the terms of the Creative Commons Attribution License (http://creativecommons.org/licenses/by/2.0), which permits unrestricted use, distribution, and reproduction in any medium, provided the original work is properly cited.

\begin{abstract}
The burden of smoking-related diseases in Jordan is increasingly evident. During 2006, chronic, noncommunicable diseases (NCDs) accounted for more than $50 \%$ of all deaths in Jordan. With this evidence in hand, we highlight the prevalence of smoking in Jordan among youth and adults and briefly review legislation that governs tobacco control in Jordan. The prevalence of smoking in Jordan remains unacceptably high with smoking and use of tobacco prevalences ranging from $15 \%$ to $30 \%$ among students aged $13-15$ years and a current smoking prevalence near $50 \%$ among men. Opportunities exist to further reduce smoking among both youth and adults; however, combating tobacco use in Jordan will require partnerships and long-term commitments between both private and public institutions as well as within local communities.
\end{abstract}

\section{Findings}

The negative health consequences of smoking and second hand smoke exposure are well documented [1-3]. The World Health Organization (WHO) estimates that there are more than one billion current smokers worldwide and that more than $80 \%$ of the world's smokers live in lowand middle-income countries [1]. An estimated 5.4 million people die from diseases directly related to cigarette smoking worldwide each year [1] and millions more are affected by the nonfatal consequences of tobacco use. Unabated, tobacco-related deaths are estimated to increase to more than eight million a year by 2030, and $80 \%$ of those deaths will occur in the developing world [1].

The burden of smoking-related diseases in Jordan is increasingly evident [4-6]. During 2006, chronic, non- communicable diseases (NCDs) accounted for more than $50 \%$ of all deaths in Jordan [7]. Deaths from heart disease and stroke (ICD-10 codes I00-I99) accounted for a third of all deaths, and malignant neoplasms (C00-C97) were responsible for about $13 \%$ of deaths, with lung cancer being the leading cause of cancer death. Nearly $60 \%$ of deaths from malignant neoplasms occurred among people younger than 65 years, and approximately one-third of those who died from heart disease and stroke were aged 65 or younger. Moreover, the economic consequences of smoking-related morbidity and mortality are profound [1]. In addition, according to national estimates, smokers in Jordan spend an estimated JD 250 million annually on tobacco products [8]. With this evidence in hand, we provide an update of the prevalence of smoking in Jordan among youth and adults. Because legislation is central to 
effective tobacco control [9], we briefly review legislation that governs tobacco control in Jordan.

For this report, data were derived from national health surveys conducted by the Jordan Ministry of Health $(\mathrm{MOH})$ as well as surveys conducted by the $\mathrm{MOH}$ in collaboration with the WHO and the United States Centers for Disease Control and Prevention (CDC).

\section{Smoking among Youth}

The prevalence of tobacco smoking among youth was obtained from two sources, the Global Youth Tobacco Survey (GYTS) and the Global School-based Student Health Survey (GSHS). The GYTS, conducted in Jordan during 1999, is a school-based survey of students aged 1315 years in public or private schools. The GSHS, also a self-administered, school-based survey conducted primarily among students 13-15 years of age, was conducted in Jordan during 2004 and 2007.

Both surveys employ a multistage sample design with schools selected proportional to enrollment size and classrooms chosen randomly within selected schools. All students in selected classes are eligible for participation, and surveys can be administered during one regular class period. During 1999, a total of 3912 students participated in the Jordan GYTS with an overall response rate of $83.9 \%$ [10]. A detailed description of the GTYS and its methodology is provided elsewhere [11]. For the 2004 Jordan GSHS, 2457 questionnaires were completed in 26 schools with an overall response rate of $95 \%$. For the 2007 Jordan GSHS, 2197 questionnaires were completed in 25 schools with an overall response rate of $99.8 \%$. Further details of the GSHS can be obtained at http://www.who.int/chp/ gshs and http://www.cdc.gov/gshs.

The estimated prevalence of ever smoking among youth is shown in Tables 1 and 2. Current smoking prevalence ranged from $18 \%$ in 1999 to about $13 \%$ in 2004 and $16 \%$ in 2007. The prevalence of current smoking was substantially greater among boys than girls, with approximately 1 in 5 boys reporting that they currently smoke compared to 7 to $10 \%$ of girls. Use of other forms of tobacco was also high among both boys and girls. Nearly 1 in 3 boys reported current use of other forms of tobacco during 2007 and roughly $17 \%$ of girls reporting current use of other forms.

\section{Smoking among Adults}

The prevalence of tobacco smoking among adults was obtained from behavioral risk factor surveys (BRFS) conducted by the Jordan MOH during 2002, 2004 and 2007. A detailed description of the Jordan BRFS is provided elsewhere [4,5,12]. Briefly, during 2002 questions about behavioral risk factors and NCD prevalence were added to the Jordan Department of Statistics' quarterly, multistage,
Table I: Prevalence of ever smoking, current smoking and current tobacco use among youth (aged 13-15 years) in Jordan, Global Youth Tobacco Survey (GYTS), 1999

\begin{tabular}{llll}
\hline & Boys & Girls & Overall \\
\hline Ever smoked cigarettes & $44.1 \%$ & $25.8 \%$ & $36.4 \%$ \\
Currently smoke cigarettes & $22.6 \%$ & $11.4 \%$ & $18.3 \%$ \\
Currently use any form of tobacco & $27.5 \%$ & $15.2 \%$ & $22.9 \%$ \\
\hline
\end{tabular}

* GYTS sample size, 3912

Source: GYTS data obtained online from: http://www.cdc.gov/ tobacco/global/GYTS/factsheets/emr/l 999/jordan factsheet.htm Accessed I I June 2009.

Notes. Lifetime prevalence of smoking was obtained from an affirmative response to the question, "Have you ever tried or experimented with cigarette smoking, even one or two puffs?". Youth were also asked the question "During the past 30 days (one month), on how many days did you smoke cigarettes?". Those who responded one ore more days were considered current smokers. Similarly, youth were asked about use of smoked tobacco products other than cigarettes (e.g. cigars, water pipe, cigarillos, little cigars, pipe) and use of any form of smokeless tobacco products (e.g. chewing tobacco, snuff, dip) during the previous 30 days. Those responding affirmatively were considered to currently use other forms of tobacco.

cross-sectional employment and unemployment survey. During 2004 and 2007, the Jordan MOH conducted its second and third BRFS, respectively, among a nationally representative sample of adults aged $\geq 18$ years. Similar to 2002, a multistage sampling design was used to select households using the master sampling frame of census enumeration blocks from the 2004 Jordan census to select the sample of blocks, or primary sampling areas, from which households were selected. In each household, one adult aged 18 years or older was randomly selected and interviewed in person in Arabic. During 2004, a total of 3520 households were selected and 3334 adults were interviewed; a response rate of $94.7 \%$. During 2007, a total of 3688 households were selected and 3654 adults were successfully interviewed; a response rate of $99.1 \%$. Smokers were classified as "ever smokers" (i.e., smokers who had smoked $\geq 100$ cigarettes during their lifetime) or "current smokers" (i.e., smokers who had ever smoked 100 cigarettes and currently smoke every day or some days).

During, 2007, nearly $40 \%$ of all adults aged 25 years or older reported having smoked at least 100 cigarettes during their lifetime (Table 2). Overall during 2007, the agestandardized prevalence of current smoking was $28 \%$ (standard error [SE], 0.86) with nearly half of men reporting current smoking behaviour compared to $5 \%$ of women (Table 3). Men aged 25-34 years had the highest $(63 \%)$ prevalence of current smoking and women aged 18 -24 years had the lowest $(<1 \%)$ prevalence (Figure 1$)$. By governorate in 2007, the age-standardized prevalence of current smoking ranged from $23 \%$ in Irbid and Tafela to $33 \%$ in Balqa and Zarqa (Figure 2). 
Table 2: Prevalence of current smoking and current tobacco use on one or more days during the 30 days preceding the survey among youth (aged I3-I5 years) in Jordan, Global School-based Student Health Survey (GSHS), 2004 and 2007

\begin{tabular}{|c|c|c|}
\hline & $\begin{array}{c}2004 \\
(n=2457)\end{array}$ & $\begin{array}{c}2007 \\
(n=2197)\end{array}$ \\
\hline \multicolumn{3}{|c|}{ Smoked cigarettes on one or more days during the 30 days preceding the survey } \\
\hline Boys & $19.2 \%(14.9-23.5)$ & $22.7 \%(|8|-27.2)$. \\
\hline Girls & $6.6 \%(3.8-9.4)$ & $8.7 \%(6.1-11.2)$ \\
\hline Overall & $12.6 \%(10.1-15.1)$ & $15.6 \%(11.0-20.2)$ \\
\hline \multicolumn{3}{|c|}{ Used any form of tobacco on one or more days during the 30 days preceding the survey } \\
\hline Boys & $28.4 \%(25.5-31.3)$ & $33.5 \%(29.2-37.9)$ \\
\hline Girls & $12.2 \%(9.9-14.5)$ & $16.5 \%(11.6-21.5)$ \\
\hline Overall & $19.9 \%(17.7-22.1)$ & $24.9 \%(19.4-30.3)$ \\
\hline
\end{tabular}

95\% confidence interval reported in parentheses

Source: GSHS data obtained online from http://www.who.int/chp/gshs/jordan/en Accessed II June 2009.

Notes. As part of the survey, youth are asked the number of days during the 30 days preceding the survey that they smoked cigarettes. Those reporting that they smoked cigarettes on one or more days were considered current smokers. Similarly, youth were asked the number of days they used any other form of tobacco during the 30 days preceding the survey.

The prevalence of current smoking was $22.8 \%$ (SE, 2.84) among adults with physician-diagnosed heart disease, $26.8 \%$ (6.81) among those with diagnosed high blood pressure, $21.3 \%$ (2.46) among those with diagnosed high blood cholesterol and 20.5\% (2.56) among those with diagnosed diabetes mellitus.

\section{Comment and note on tobacco legislation, control policies, programmes in Jordan}

The well-known adverse effects of smoking and the documented benefits of quitting [13] notwithstanding, the prevalence of smoking among Jordanian youth and adults remains high. Smoking behavior among women may be higher than that reported here as women may deny their smoking behavior and/or underestimate their frequency of smoking. As a result of second-hand smoking, women's smoking exposure almost certainly exceeds that reflected in their own smoking behaviour. The prevalence of smoking among young and middle aged Jordanian men is similar to that of the US adult population during the late 1960 s/early 1970s [14]. In Egypt the prevalence of lifetime smoking was $20 \%$ among boys and $5 \%$ among girls according to data from the 2005 GYTS while the prevalence among men (aged 15-65 years) was 34\% according

Table 3: Survey participant characteristics and age-specific and age-standardized smoking prevalences among adults aged 18 years or older by participant characteristics, Behavioral Risk Factor Surveillance System, Jordan, 2007

\begin{tabular}{|c|c|c|c|}
\hline Characteristic & 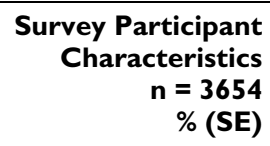 & $\begin{array}{r}\text { Prevalence of Lifetime } \\
\text { Smoking } \\
n=1409 \\
\%(\mathrm{SE})\end{array}$ & $\begin{array}{r}\text { Prevalence of Current } \\
\text { Smoking } \\
\mathbf{n}=1080 \\
\% \text { (SE) }\end{array}$ \\
\hline \multicolumn{4}{|l|}{ Age, yrs } \\
\hline $18-24$ & $14.9(0.64)$ & $25.0(1.96)$ & $23.4(1.95)$ \\
\hline $25-34$ & $19.6(0.76)$ & $41.0(2.13)$ & $37.2(2.06)$ \\
\hline $35-44$ & $26.7(0.80)$ & $40.7(1.60)$ & 32.9 (1.57) \\
\hline $45-54$ & $15.4(0.62)$ & $38.6(2.16)$ & $28.5(2.02)$ \\
\hline $55-64$ & $12.7(0.58)$ & $39.6(2.61)$ & $23.6(2.29)$ \\
\hline$\geq 65$ & $10.8(0.58)$ & $40.3(2.97)$ & $19.4(2.39)$ \\
\hline \multicolumn{4}{|l|}{ Gender* } \\
\hline Men & $53.1(0.87)$ & $61.8(1.21)$ & $48.2(1.27)$ \\
\hline Women & $46.9(0.87)$ & $7.8(0.67)$ & $5.1(0.54)$ \\
\hline \multicolumn{4}{|l|}{ Education* } \\
\hline Never attended school & I I.4 (0.58) & $24.7(4.98)$ & $18.6(4.83)$ \\
\hline Primary school & $32.0(0.87)$ & $44.1(1.74)$ & $35.3(1.90)$ \\
\hline Secondary or technical schoola & $42.7(0.87)$ & $36.5(1.56)$ & $26.8(1.47)$ \\
\hline University or more & $13.9(0.75)$ & $44.7(2.30)$ & $29.8(2.18)$ \\
\hline
\end{tabular}

$\mathrm{SE}$, standard error

Note: Current smoker defined as having ever smoked >100 cigarettes in lifetime and currently smoke every day or some days; former smoker defined as having ever smoked $>100$ cigarettes in lifetime but not currently smoking

* Prevalence of smoking is age-standardized 


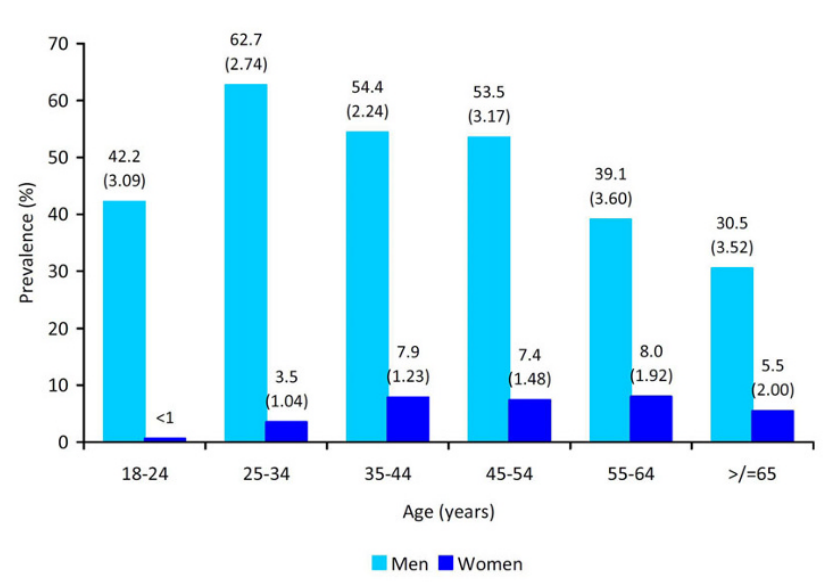

Figure I

Age-specific current smoking prevalence among adults aged 18 years or older by gender, Behavioral Risk Factor Surveillance System, Jordan, 2007.

to data from the WHO's Global Infobase https:// apps.who.int/infobase/report.aspx. Similarly high prevalences have been observed among boys (45\% ever smoked, 25\% currently smoke, 2006 GYTS) and men (20\%-42\% currently smoke, 2006/7 Iraq Family Health Survey; men aged 19-64 years) in Iraq.

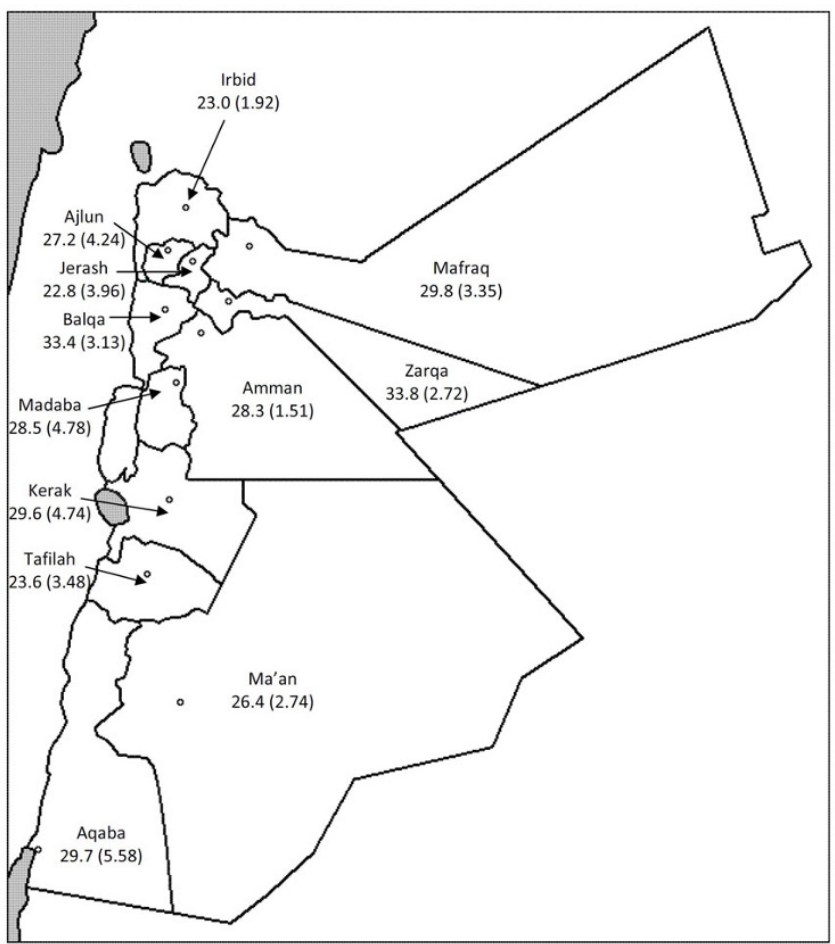

Figure 2

Age-standardized current smoking prevalence among adults aged 18 years or older by governorate, Behavioral Risk Factor Surveillance System, Jordan, 2007.
The relatively lower prevalence rate of current smoking in patients with prevalent heart disease and heart disease risk factors in Jordan is easy to explain on the basis of patients quitting the habit after diagnosis with these conditions. In addition, poor survival of smokers suffering from heart disease and its risk factors may, in part, provide another explanation. Smoking cessation is essential for patients with CHD. However, current smoking remained unacceptably high in these patients. Current guidelines recommend that clinicians ask about tobacco use and provide counseling about quitting within the context of a comprehensive plan for secondary prevention $[15,16]$. Available strategies include identifying and documenting smoking status in all patients, referral for consultation and counseling, prescription of appropriate drugs in accordance with clinical guidelines, and the provision of quit lines and community support services [17]. In addition, initiatives to promote cessation at the work site are needed, as is enforcement of smoke-free legislation in schools and public places.

Jordan has an extensive history with tobacco control policies and programmes that have shaped its current tobacco control infrastructure. Jordan's initial anti-smoking regulation was part of a public health law issued in 1971. This initial legislation established jail sentences not exceed four months or fines (ranging from JD 25 to JD 500 , or both penalties, [ 1 Jordanian Dinar (JD) $=1.41$ US dollars]) but was challenged by the absence of enforcement mechanisms and application of penalties for those who smoked in public places and on public transport or promoted tobacco use through advertisements. In November 2001, legislation, included as part of Juvenile Monitoring Legislation, was put in place to restrict tobacco sales to minors with penalties for minors (e.g., a JD 20 fine for a first-time violation; fine doubled if the offence were to be repeated) and for the vendor (e.g., a JD 100 fine and a jail sentence of up to one year). In May 2003, Jordan adopted the Framework Convention on Tobacco Control (FCTC) with a tobacco control strategy that included a general ban on tobacco advertising, raising of public awareness on the hazards of tobacco use, enforcement of legislation, and encouragement of smoking cessation, among others. (N.B. The 2003 tobacco control country profile can be found online at http:// www.who.int/tobacco/media/en/Jordan.pdf.) For example, a picture warning that covers $50 \%$ of the package size is now required on all cigarette packages in Jordan.

More recently (in 2008), Jordan's public health law was amended to prohibit smoking in public and private institutions and all public facilities including hospitals, healthcare centres, schools, cinemas, theatres, libraries, museums, public and nongovernmental buildings, public transport vehicles, airports, closed playgrounds, lecture 
halls and any other location at the discretion of the Minister of Health. Smoking is also prohibited inside Amman's shopping malls, and in addition to posted warning signs, the $\mathrm{MOH}$ has required five star restaurants in Amman to identify smoke-free places for non-smokers. Beginning June 2009, smoking was banned inside Amman's fast-food outlets. 'No smoking' signs were widely distributed and posted in every $\mathrm{MOH}$ facility, other major health facilities (hospitals, large health centres, etc), airports, and other venues. Penalties were established in this section in more formative way compared with prior legislation. In addition, the new legislation provided clear mechanisms for organizing the supervision and monitoring of the smoking ban. For example, the prohibition of smoking among staff in health facilities in the country was accompanied by a decision by the Minister of Health to penalize Ministry staff who smoked in health facilities both administratively and monetarily through reductions in wages and benefits. At the international airport, where smoking is now prohibited with the exception of designated smoking areas, focal points for monitoring adherence were also assigned. Effectiveness of these policies, however, remains to be measured.

In conclusion, while the current infrastructure for tobacco control is a beginning, opportunities remain to improve anti-smoking policies and programmes particularly in areas of enforcement. The prevalence of smoking in Jordan, particularly among men, remains unacceptably high, and opportunities exist to further reduce smoking among both youth and adults and particularly among patients with smoking-related diseases. Of course, it is hoped that the tobacco control policies will, in part, result in a reduction in smoking prevalence; however, such policies cannot work in isolation. Socio-cultural norms, whereby smoking among men is a common and accepted part of daily life with little or no societal perception of smoking as a negative behaviour, present a challenge to tobacco control. Ultimately, smokers must decide that they need to quit smoking. Smoking cessation programmes that offer free-of-charge counseling and nicotine replacement medication for those who wish to quit smoking as well as quit hotlines have been implemented in Jordan in the past, but their widespread use has not been sustained and some suggest that additional effort is needed to educate and counsel health professionals as well as provide them the necessary behavioral intervention skills for smoking cessation [18]. Effective tobacco-related awareness programmes, particularly anti-tobacco peer education programmes targeting youth, must be implemented more widely across the country. Combating tobacco use in Jordan will require partnerships and long-term commitments between both private and public institutions as well as within local communities.

\section{Competing interests}

The authors declare that they have no competing interests.

\section{Authors' contributions}

Study conception and design: AB, MAN, DWB. Acquisition of data: $A B, M A N$. Analysis and interpretation of data: MAN, DWB. Drafting of manuscript: AB, MAN, AB, DWB, HTW. Critical revision: AB, MAN, AB, DWB, HTW. All authors read and approved the final manuscript.

\section{Acknowledgements}

The findings and conclusions in this report are those of the authors and do not necessarily represent the official position of the Centers for Disease Control and Prevention.

\section{References}

I. World Health Organization: WHO Report on the Global Tobacco Epidemic, 2008: the MPOWER package Geneva, Switzerland: WHO Press; 2008.

2. U.S. Department of Health and Human Services: The Health Consequences of Smoking: A Report of the Surgeon General Atlanta, Georgia, USA: U.S. Department of Health and Human Services, Centers for Disease Control and Prevention, National Center for Chronic Disease Prevention and Health Promotion, Office on Smoking and Health; 2004

3. U.S. Department of Health and Human Services: The Health Consequences of Involuntary Exposure to Tobacco Smoke: a Report of the Surgeon General Atlanta, Georgia, USA: U.S. Dept. of Health and Human Services, Centers for Disease Control and Prevention, Coordinating Center for Health Promotion, National Center for Chronic Disease Prevention and Health Promotion, Office on Smoking and Health; 2006.

4. Shehab F, Belbeisi A, Walke H: Prevalence of selected risk factors for chronic disease--Jordan, 2002. MMWR Morb Mortal Wkly Rep 2003, 52: 1042-1044.

5. Belbeisi A, Zindah M, Walke H, Jarrar B, Mokdad AH: Assessing risk factors for chronic disease--Jordan, 2004. MMWR Morb Mortal Wkly Rep 2006, 55:653-655.

6. Nsour M, Mahfoud Z, Kanaan MN, Balbeissi A: Prevalence and predictors of non-fatal myocardial infarction in Jordan. Eastern Mediterranean Health J 2008, I 4:818-830.

7. Jordan Ministry of Health, Directorate of Information and Research: Mortality data in Jordan, 2006. Information and Research Newsletter 2009, I: I-4

8. Experts tackle religious, health issues on smoking The Jordan Times; 2002.

9. Tobacco Free Initiative: the importance of legislation [http:/ /www.who.int/tobacco/research/legislation/importance/en/ index.html]

10. Global Youth Tobacco Survey, Jordan Fact Sheet [http:// www.cdc.gov/tobacco/global/GYTS/factsheets/emr//999/ jordan factsheet.htm]

II. Global Youth Tobacco Survey Collaborating Group: Differences in worldwide tobacco use by gender: findings from the Global Youth Tobacco Survey. J Sch Health 2003, 73:207-2I 5.

12. Zindah M, Belbeisi A, Walke H, Mokdad AH: Obesity and diabetes in Jordan: findings from the behavioral risk factor surveillance system, 2004. Prev Chronic Dis 2008, 5:AI7.

13. Wilson K, Gibson N, Willan A, Cook D: Effect of smoking cessation on mortality after myocardial infarction: meta-analysis of cohort studies. Arch Intern Med 2000, I 60:939-944.

14. Trends in Current Cigarette Smoking Among High School Students* and Adults, $\dagger$ United States, I 965-2007 [http:// www.cdc.gov/tobacco/data statistics/tables/trends/cig smoking]

15. Smith SC Jr, Allen J, Blair SN, Bonow RO, Brass LM, Fonarow GC Grundy SM, Hiratzka L, Jones D, Krumholz HM, Mosca L, Pasternak RC, Pearson T, Pfeffer MA, Taubert KA: AHA/ACC guidelines for secondary prevention for patients with coronary and other atherosclerotic vascular disease: 2006 update: endorsed by the National Heart, Lung, and Blood Institute. Circulation 2006, I | 3:2363-2372. 
16. Fiore MC, Bailey WC, Cohen SJ, Dorfman SF, Goldstein MG, Gritz ER, Heyman RB, Jaén CR, Kottke TE, Lando HA, Mecklenburg RE, Mullen PD, Nett LM, Robinson L, Stitzer ML, Tommasello AC, Villejo L, Wewers ME: Treating tobacco use and dependence: clinical practice guideline. 2000 [http://www.surgeongeneral.gov/tobaccol treating tobacco use.pdf]. Rockville Maryland, USA: U.S. Department of Health and Human Services, Public Health Service Accessed May 6, 2009

17. Centers for Disease Control and Prevention: Telephone Quitlines: A Resource for Development, Implementation, and Evaluation Atlanta, Georgia, USA: US Department of Health and Human Services, Centers for Disease Control and Prevention, National Center for Chronic Disease Prevention and Health Promotion, Office on Smoking and Health, Final Edition; 2004.

18. Shishani K, Nawafleh H, Froelicher ES: Jordanian nurses' and physicians' learning needs for promoting smoking cessation. Prog Cardiovasc Nurs 2008, 23:79-83.

Publish with Bio Med Central and every scientist can read your work free of charge

"BioMed Central will be the most significant development for disseminating the results of biomedical research in our lifetime. "

Sir Paul Nurse, Cancer Research UK

Your research papers will be:

- available free of charge to the entire biomedical community

- peer reviewed and published immediately upon acceptance

- cited in PubMed and archived on PubMed Central

- yours - you keep the copyright

Submit your manuscript here:

http://www.biomedcentral.com/info/publishing_adv.asp
BioMedcentral 